\title{
ВОЗМОЖНОСТИ ВАРИАТИВНОГО ОБРАЗОВАНИЯ В ПОДГОТОВКЕ БУДУЩИХ УЧИТЕЛЕЙ ИНОСТРАННОГО ЯЗЫКА
}

\section{POSSIBILITIES OA VARIABLE EDUCATION IN THE TRAINING OF FUTURE FOREIGN LANGUAGE TEACHERS}

\section{S. Kanina \\ E. Yermolayeva G. Gmyzina}

Summary: The article discusses the various possibilities of variable education in the field of «Foreign languages» in the training of future teachers. The authors analyse the positive and negative trends that exist in distance and mixed teaching of foreign languages in higher education institutions.

Keywords: variable education, the methodology of foreign language teaching, information technology, internet technology, distance learning, online learning, blended learning.
Канина Светлана Юрьевна

К.n.н., дочент, ФГБОУ ВО «Ульяновский государственный педагогический университет имени И.Н. Ульянова»

kmasu@yandex.ru

Ермолаева Елена Владимировна

К.п.н., доцент, ФГБОУ ВО «Ульяновский государственный педагогический университет имени И.Н. Ульянова»

e_jermolajeva@mail.ru

Гмызина Галина Николаевна

К.n.н., дочент, ФГБОУ ВО «Ульяновский государственный педагогический университет имени И.Н. Ульянова»

gng13@mail.ru

Аннотация: В статье рассматриваются различные возможности вариативного образования в сфере «Иностранные языки» в подготовке будущих учителей. Авторы анализируют положительные и отрицательные тенденции, существующие в дистанционном и смешанном обучении иностранным языкам в высших учебных заведениях.

Ключевые слова: вариативное образование, методика обучения иностранным языкам, информационные технологии, интернет-технологии, дистанционное обучение, онлайн-обучение, смешанное обучение.

собные принести пользу в обучении.

В онлайн-обучении ключевым элементом является использование интернета. Лекции, тесты и практические задания размещаются на онлайн платформе, что позволяет обучающимся выполнять задания в любом удобном для них месте и времени и при наличие любого гаджета, в котором имеется доступ к интернету.

Дистанционное обучение понимается и часто используется как синоним онлайн-обучения. Дистанционное обучение - «взаимодействие учителя и учащихся между собой на расстоянии, отражающее все присущие учебному процессу компоненты (цели, содержание, методы, организационные формы, средства обучения) и реализуемое специфичными средствами интернеттехнологий или другими средствами, предусматривающими интерактивность» [1]. Онлайн обучение является частью дистанционного обучения, но так как задание в настоящее время удобнее отправить посредством интернета, то онлайн обучение и дистанционное обучение воспринимаются как синонимы.

Первый университет, предложивший дистанционное обучение, был the Open University в Великобритании, который уже 50 лет дает образование, используя информационные технологии. Представители the Open University верят, что информационные технологии могут принести 
пользу в обучении людей на высоком уровне, особенно тех, которые по разным причинам не могут посещать занятия. До сегодняшнего дня университет привлекает студентов со всего мира, готовых получать образование на высоком уровне благодаря образовательным онлайн и дистанционным программам. К тому же, the Open University входит в 50 лучших университетов Великобритании.

Стоит отметить, что количество университетов, предлагающих дистанционное образование, растет с каждым днем не только в Великобритании, но и в Европе в целом. Появились такие университеты и в России. В университетах Великобритании, США, Канады, Австралии, Германии, Франции доступно большое количество курсов дистанционного обучения для бакалавров, а некоторые из них можно найти в учебных заведениях Ирландии, Нидерландов и Швейцарии. Университеты предлагают дистанционное обучение по всем направлениям и на всех уровнях, начиная с уровня бакалавра, и заканчивая уровнем доктора наук.

Преимущества подобных университетов, предлагающих дистанционное обучение, очевидно. Такое обучение очень удобно для тех студентов, которые работают параллельно с учебой. Возможности посещать и находиться на занятиях весь день у таких студентов нет. Даже если они работают в вечернее время, прийти на 1 и 2 пару иногда не представляется возможным. Известно, что студенты часто пропускают занятия по причинам личного характера или просто по болезни. Не каждый преподаватель с сочувствием и пониманием относятся к подобным проблемам.

Дистанционное обучение - возможность учиться в любой точке мира без особых затрат. Если хотите жить в Пакистане, но учиться в Нидерландах, программа дистанционного обучения позволит вам это сделать без проблем.

Одна из наиболее важных причин, по которой образовательная онлайн-программа имеет преимущества перед традиционным обучением - это большая гибкость. Дистанционное обучение позволяет легче совмещать свою карьеру с получением университетской или научной степени. Некоторые университеты дистанционного обучения предлагают несколько дат и мест проведения обязательных собраний в университете, поэтому студент может выбрать наиболее удобные для себя варианты.

Диапазон программ дистанционного обучения, предлагаемых университетами по всему миру, может быть огромным. Но учитывая специфику обучения иностранному языку, можно предположить, что онлайн и просто дистанционное обучение будет не очень эффек- тивным. Смешанное обучение является лучшим для обучения иностранным языкам. Смешанное обучение это образовательный подход, совмещающий обучение с участием учителя (лицом-к-лицу) с онлайн-обучением и предполагающий элементы самостоятельного контроля учеником пути, времени, места и темпа обучения, а также интеграцию опыта обучения с учителем и онлайн [1]. N.Friesen подчеркивает, что смешанное обучение представляет собой «диапазон возможностей, представленных путём объединения интернета и электронных средств массовой информации, с формами, требующими физического соприсутствия в классе преподавателя и учащихся» [2].

Преимущества смешанного обучения («blending teaching»), в частности, иностранному языку очевидны. Смешанное обучение предполагает не просто обучение с использованием онлайн технологий, но и самообучение по новой, более творческой методике. Это требует нового подхода, как со стороны преподавателей, так и учащихся. Время, проведенное в классе, в ходе смешанного обучения, можно использовать более рационально на интерактивную работу со студентами, а работа на усвоение лексических и грамматических навыков выполняется самостоятельно в удобное для студентов время. В связи с этим подходом роль учителя меняется от простого передатчика знаний на «координатора»-помощника в освоении новых знаний.

Обучение иностранному языку требует особого контроля со стороны учителя. Во-первых, обучение слухопроизносительным навыкам невозможно без учителя. Любые обучающие онлайн программы объясняют и даже произносят звуки, но только учитель услышит неправильное произношение и исправит его. Даже объяснение и отработка грамматического материала доступнее для понимания, когда дается традиционными методическими приемами в классе.

Студенты, учась в педагогическом ВУЗе, видят работу преподавателя практически ежедневно и у них складываются определенные представления о сложностях и проблемах как самой профессии, так и о работе с людьми в целом. Проблема преподавателя-координатора становится еще более актуальной, когда встает вопрос о том, как предоставить студенту возможность опыта практической деятельности при сокращенном количестве аудиторных часов дистанционных программ? Большинство учебных предметов педагогических вузов нацелены на овладение практическими навыками, т.к. студентам необходимо не только получить теоретические знания в своей сфере, но и уметь донести эти знания до своих учеников в школе. Так возникает диссонанс между огромным потенциалом не только дистанционного, но и смешанного обучения с точки зрения освоения изучаемого иностранного языка и потребностями в на- 
работке практического опыта его использования в своей будущей профессии будущими учителями.

Таким образом, вопрос использования смешанного обучения иностранным языкам в педагогическом ВУзе остается открытым, но определенно можно сказать, что обучение некоторым предметам с частичным использованием интернет технологий не исключается.

\section{ЛИТЕРАТУРА}

1. Дистанционное обучение [электронный ресурс] - Режим доступа: https://ru.wikipedia.org

2. Friesen, N. Report: Defining Blended Learning [электронный ресурс] - Режим доступа: https://www.normfriesen.info/papers/Defining_Blended_Learning_ NF.pdf

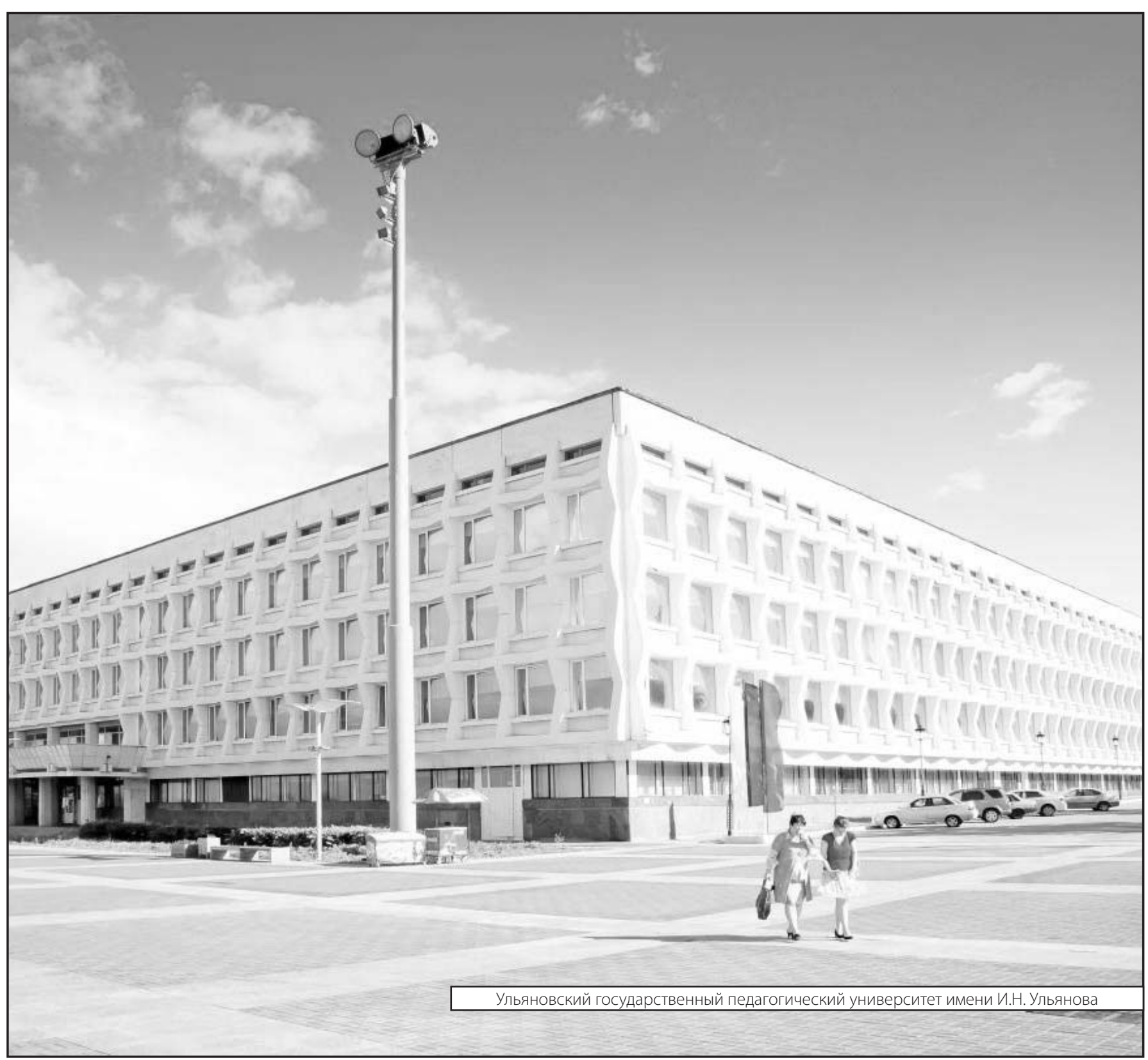

